Full Length Article

\title{
Development of Plant Expression Vector with Taq DNA Polymerase Gene to Yield Heat-tolerant Maize Lines
}

\author{
Ya-Jun Zhang, Ling-Yan Zhou, Yu-Xian Bai, Wen-Bin Yi, Kun Cu, Xiaoxiong Nie and Xue-Lian Liang* \\ College of Life Science, Zhongkai University of Agriculture and Engineering, Guangzhou 510225, China \\ *For correspondence: Liangxuelian2005@sina.com
}

\begin{abstract}
Thermus aquaticus (Taq) DNA polymerase has been extensively used in DNA amplification procedures, However, the application of Taq DNA polymerase gene in plant has not yet been reported. In this study, we have focused on using Taq DNA polymerase gene to develop heat-tolerant maize transgenic lines, which would aid in controlling crop loss due to heat stress and potentially increase the economic value. Firstly, an expression vector with Taq DNA polymerase gene was constructed and introduced into the maize ZhongKai inbred lines, Zhong sweet No. 1 and Zhong glutinous No. 2 by pollen-mediated transformation to obtain the transgenic maize plants. Then, the harvested T1 generation seeds were confirmed to be positive transformants by PCR and Southern blotting. The screening of the T2 generation by exposure to heat stress conditions in the field combined with physiological indexes resulted in nine heat-tolerant transgenic maize lines. The expression vector with Taq DNA polymerase gene, developed in the present study, will certainly expand more avenues for heat-tolerant genetic transformation in plants. (C) 2017 Friends Science Publishers
\end{abstract}

Keywords: Maize; Taq DNA polymerase gene; Pollen-mediated transformation; Heat-tolerance

\section{Introduction}

The heat shock response is commonly believed to be dominated by multiple genes. When plants are stimulated by heat, the heat shock factors may specifically combine with the binding sites, thereby activating the expression of the genes that encode heat shock proteins (HSP) and promote the accumulation of these proteins in vivo. This phenomenon leads to an improvement of heat tolerance in plants (Morimoto, 1998; Hartl and Hayer-Hartl, 2002; Andrade et al., 2013). On the contrary, two different studies have shown that under heat stress, the species that can produce new proteins harbor genes with poor heat tolerance (Stout and Al-Niemi, 2002; Mishra and Grover, 2016), have shown that under heat stress, the species that can produce new proteins harbor genes with poor heat tolerance. Their results demonstrated that most of the proteins synthetized at room temperature, can also be synthetized under heat stress, since it is a response to high temperature in species with poor heat tolerance. These findings were found to be consistent with previous reports (Freiden et al., 1992; Wahid et al., 2007), which also suggested that the phenomenon of heat tolerance is not limited to HSP alone.

Taq DNA polymerase is isolated from the thermophilic bacteria, Thermophilus aquaticus, and has a stable natural structure. It can synthesize arbitrary sequence of DNA under high temperature in vitro and presents fidelity to its replicated templates. It is a key ingredient of polymerase chain reaction (PCR) and at present, its application is confined to this technique. Interestingly, Yang et al. (1995) established a "PCR-like system" without template and primers, and proved that Taq DNA polymerase can mediate spontaneous enzymatic synthesis of DNA. Meanwhile, a higher dose of enzyme, higher reaction temperature, and prolonged heat preservation time were considered favorable for the synthesis of small DNA molecules. These observations further corroborated the findings of Schachman (Schachman et al., 1960). For the amplified DNA sequences of sizes less than $194 \mathrm{bp}$ and of the range, $603 \mathrm{bp}-4.3 \mathrm{~kb}$, the corresponding protein molecular weights obtained were smaller than 8.4 KD and between 20.4 KD and $120 \mathrm{KD}$, respectively (Yang et al., 1995). The sizes of these proteins were found to be similar to the sizes of the HSP detected in the Yang et al. (1995) experiment.

Currently, the transgenic methods commonly used for most of the plants include the Agrobacterium tumefaciens mediated technique and particle bombardment. These two methods require tedious and lengthy tissue culture procedures and are carried out by applying the callus as a receptor, which may in turn induce somatic variations and is genotype dependent (Frame et al., 2011; Omer et al., 2013). Although bombardment is not restricted by hosts, it is likely to cause damage and mutations. A. tumefaciens has a natural transformation mechanism to develop a single copy, but

To cite this paper: Zhang, Y.J., L.Y. Zhou, Y.X. Bai, W.B. Yi, K. Cu, X. Nie and X.L. Liang, 2017. Development of plant expression vector with taq DNA polymerase gene to yield heat-tolerant maize lines. Int. J. Agric. Biol., 19: 523-527 
maize is not a natural host for Agrobacterium (Jackson et al., 2013). Various improvement methods, such as adding Acetosyringone (Sheikholeslam and Weeks, 1987), screening strains, and utilizing binary vector (Miller et al., 2002; Vega et al., 2008; Deeba et al., 2014) have been adopted in the infection process; however, the transformation ratio still remains low. Among the reproductive system transformation methods, the first proposed pollen-tube pathway (Zhou, 1983) showed a great success in cotton (Yang et al., 2007). Further, pollenmediated transformation was proposed based on the blooming characteristics of maize; therefore, the operation was observed to be more suitable for the transformation of plants, especially for maize, which produced large amounts of pollen (Eapen, 2011).

The question that whether Taq DNA polymerase gene can be directly applied to promote normal DNA replication in plant cells under heat stress, still needs to be answered. The present study was therefore undertaken in order to investigate the phenomenon of spontaneous synthesis of DNA in plants in vivo under heat stress conditions. The maize transformation experiment was done by producing an expression vector with Taq DNA polymerase gene using pCAMBIA1380 as the binary vector. This vector system was then transformed into maize inbred lines using the pollen-mediated method. The use of molecular techniques and exposure to high temperature conditions in the field further facilitated to screen and obtain the heat-tolerant maize lines.

\section{Materials and Methods}

\section{Plants and other Experimental Materials}

Zhong sweet No. 1 and Zhong glutinous No. 2 inbred lines was used for the experiments in this study. All maize plants were cultivated in field and bagged during flowering period. Escherichia coli strain DH5a was used for the cloning. The pCAMBIA1380 was used as the binary vector for pollenmediated transformation.

\section{Establishment of Binary Expression Vector}

Based on the $2.5 \mathrm{~kb}$ gene sequence information of Taq DNA polymerase gene (Di et al., 2012), a pair of primers (Taq1: 5'-GGCCGAATTCATGCTGCCCCTCTTTGAGCCC-3') and Taq2: GGCCGAATTCTCACTCCTTGGCGGAGAGCC-3') were designed, with $E c o$ RI located at each end of the gene. PCR was performed in a $25 \mu \mathrm{L}$ reaction containing $1 \mu \mathrm{L}$ of plasmid containing Taq DNA polymerase gene as the template, $18.5 \mu \mathrm{L}$ of $\mathrm{ddH}_{2} \mathrm{O}, 2.5 \mu \mathrm{L}$ of $10 \times \mathrm{PCR}$ buffer, 0.5 $\mu \mathrm{L}$ of dNTP mix (10 mM each), $1 \mu \mathrm{L}$ of primer Taq 1 (10 $\mu \mathrm{M}), 1 \mu \mathrm{L}$ of primer Taq $2(10 \mu \mathrm{M})$, and $0.5 \mu \mathrm{L}$ of DNA polymerase $(2.5 \mathrm{U} / \mu \mathrm{L}$; Takara, Dalian, China). PCR was performed using the following cycling profile: $94^{\circ} \mathrm{C}$ for 5 min, 36 cycles at $94^{\circ} \mathrm{C}$ for $1 \mathrm{~min}, 56^{\circ} \mathrm{C}$ for $1 \mathrm{~min}, 72^{\circ} \mathrm{C}$ for $4 \mathrm{~min}$, and then $72^{\circ} \mathrm{C}$ for $10 \mathrm{~min}$. The PCR amplicons about 2.5kb DNA fragment (Fig. 1B) were sequenced by Dingguo Biotechnology Co. (Beijing, China). Preparation of competent E. coli cells, as well as the insertion of PCR amplicons into the pUC19 vector, were carried out based on the protocols reported by $\mathrm{Li}$ and $\mathrm{Liu}$ ( $\mathrm{Li}$ and $\mathrm{Liu}, 2004)$. The recombinant plasmids was firstly screened by Blue-white screening (Fig. 1C) method (Stout and Al-Niemi, 2002) and further confirmed by PCR (Fig. 1D). Then, the gene fragment was recycled (Fig. 1E) and inserted into pCAMBIA1380 binary vector to yield the expression vector pCAMBIA1380-Taq.

\section{Maize Transformation by Pollen-mediated Method}

Approximately $0.1 \mathrm{~g}$ of fresh pollen was collected at 8-9 $\mathrm{AM}$ and stored in $5 \mathrm{~mL}$ of $10 \%$ sucrose solution. Subsequently, the pollen grains were mixed with $50 \mu \mathrm{g}$ plasmid DNA followed by being treated twice using ultrasonication $(200 \mathrm{~W}, 5$ seconds each time and at an interval of $3 \mathrm{sec}$ ). Then, the precipitated pollen and the remaining solution were transferred to a petri dish for artificial pollination. In this experiment, 20 ears with filament length of $3-5 \mathrm{~cm}$ were selected. The pollen solution following ultrasonic treatment was applied to the filaments using a brush for artificial pollination. The ear bags were hitched and labeled to record data on burliness.

\section{PCR and Southern Blotting Detection of Transformants}

Seedling leaf DNA extraction of T1 and T2 generation of transformants was performed with improved SDS alkaline lysis (Wang et al., 2007). The PCR amplification of T1 and $\mathrm{T} 2$ generation was carried out in a $25 \mu \mathrm{L}$ mixture with an annealing temperature of $56^{\circ} \mathrm{C}$. For Southern blotting of $\mathrm{T} 1$ generation of transformants, $20 \mu \mathrm{g}$ of DNA were digested with $E c o$ RI to hybridization with probes. The probes from the plasmids was labeled using the PCR digoxin probe labelling kit, and the random primers method was used to label the molecular weight marker. The Chemiluminescent detection (CSPD) method was used for color development (Liang et al., 2016).

\section{Screening of Maize for Heat Tolerance}

T2 generation of transformants was sown on March 25, that was 15 days later than the normal spring seeding, and the study was conducted at the experimental plots of Zhongkai University of Agricultural and Technology, China between 2010 2013. The growth robustness, extent of damage and pollen quantity were observed and divided into three grades: (i) Bad, no anther spited, no pollen, short, with yellow-green blades; (ii) Moderate, anther spited but thin and shriveled, small amount pollen, weak blades; (iii) Normal, lots of pollen, dark green upright blade 
(Chen et al., 2010).

The number of kernels was recorded after the maize ears were harvested (Kaur and Saxena, 2008). Furthermore, the leaves were sampled at the plant flowering stage to determine the physiological parameters. Of which, the superoxide dismutase (SOD) activity was measured by nitro blue tetrazolium (NBT) photo reduction, and the malondialdehyde (MDA) concentration was determined by thiobarbituric acid spectrophotometric method (Li et al., 2002).

\section{Results}

\section{Acquisition of Taq DNA Transgenic Plants}

To obtain the transgenic plants of Taq DNA polymerase gene, we firstly amplified the target gene from plasmid containing Taq DNA polymerase gene (Fig. 1B), which was confirmed by sequencing. Subsequently, the gene fragment amplified above was connected to plasmid vector pUC19 and then inserted into pCAMBIA1380. The results of EcoRI digestion identification indicated that the expression vector, pCAMBIA1380-Taq was successfully established (Fig. 1A). The transformed maize ears using pollen-mediated method were harvested (Fig. 2).

\section{Confirmation of Taq DNA Transgenic Lines}

To investigate positive transformed maize, a PCR analysis of $\mathrm{T} 1$ generation was performed. The results showed that a total of 18 plants were successfully amplified to obtain the expected band (Fig. 3A). To confirm the PCR results and further determine the precise copy of the transferred gene, Southern blotting of the T1 generation was conducted (Fig. $3 \mathrm{~B})$. The results indicated that the target gene was integrated into the genome of the transformed plants, and all of positive transformants were one copy insertion. Totally, six positive T1 lines from 18 PCR positive plants were obtained.

\section{Screening of Maize for Heat-tolerance in the Field}

To investigate the growth of the plant and pollen quantity under high temperature stress, we postponed sowing the T2 generation of transgenic plants and make the flowering period delayed to mid-June, when the average temperature was $33^{\circ} \mathrm{C}, 0.5-1^{\circ} \mathrm{C}$ higher than normal sowing time; and the filling period was in late June, the average temperature was $33.2^{\circ} \mathrm{C}, 0.5-2^{\circ} \mathrm{C}$ higher than normal sowing time, which resulted in a moderate damage on maize. Consistent with PCR detection results (Table 1), some of T2 generation plants were short, with yellow blades and weak growth vigor, and not tassel and no pollen, which was similar to the control. However, some of these had relatively strong growth vigor, with dark green and upright blades, and much more pollen that could be pollinated and fertilized (Fig. 4).
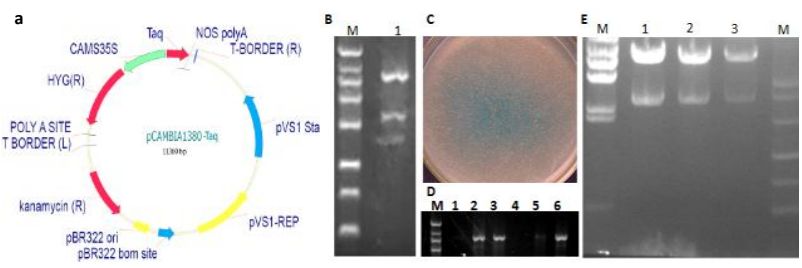

Fig. 1: Establishment of binary expression vector A. Structure of binary vector pCAMBIA1380-Taq; B. PCR amplification of the Taq DNA polymerase gene; C. Blue-white screening; D. PCR identification of recombinant plasmids; E. Digestion identification of pCAMBIA1380-Taq

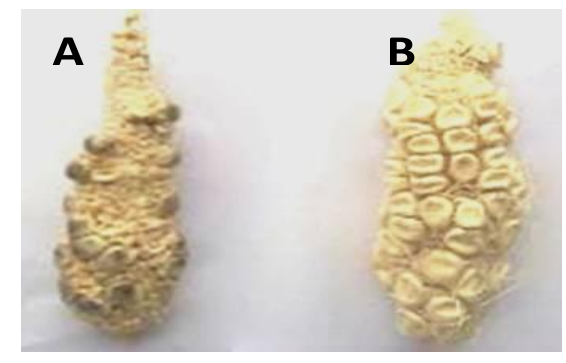

Fig. 2: Ears of transgenic plants

A: Zhong glutinous No.1, B: Zhong sweet No. 2

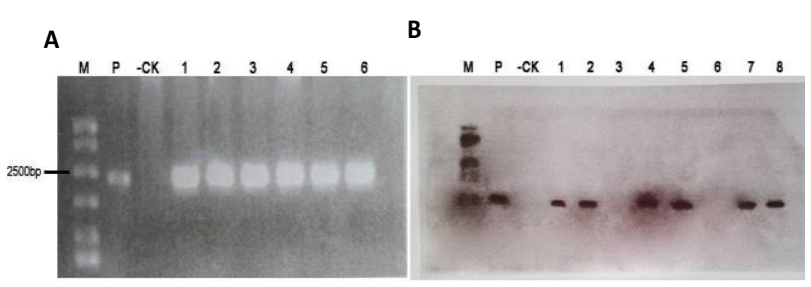

Fig. 3: Detection of $T 1$ generation transgenic plants A. PCR detection; B. Southern hybridization. M: Marker, P: Plasmid, -CK: Negative control, 1-8: Transgenic plants

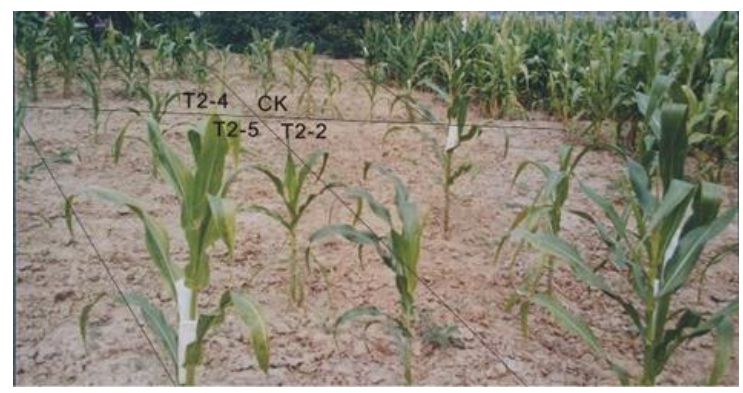

Fig. 4: High temperature screening of $\mathrm{T} 2$ generation in field

\section{Analysis of Heat Tolerance Index}

To confirm the heat-tolerant screening, heat tolerance index such as SOD activity and MDA concentration of the transgenic plants were conducted (Table 1) on June 15 (during the flowering period), when the maximum 
Table 1: PCR positive rate and heat-tolerant screening of $T_{2-4}$ line of $T_{2}$ generation plants

\begin{tabular}{|c|c|c|c|c|c|c|c|}
\hline $\begin{array}{l}\text { Identity of } \\
\mathrm{T} 2 \text { - } 4 \text { line }\end{array}$ & $\begin{array}{l}\mathrm{PCR} \\
(+,-)\end{array}$ & Blossom SOD (U/g)* & $\begin{array}{l}\text { MDA concentration } \\
(\mathrm{nmol} / \mathrm{g})^{*}\end{array}$ & Growth & Pollination & $\begin{array}{l}\text { Kernel number per } \\
\text { panicle (n) }\end{array}$ & Resistance line \\
\hline 1 & - & $143.22 \mathrm{fg}$ & $46.78 \mathrm{a}$ & $\mathrm{Bad}$ & Few & 8 & \\
\hline 2 & + & $175.03 \mathrm{~d}$ & $17.09 \mathrm{c}$ & Moderate & Moderate & 12 & \\
\hline 3 & + & $226.00 \mathrm{bc}$ & $15.25 \mathrm{~d}$ & Normal & Many & 19 & \\
\hline 4 & - & $135.17 \mathrm{~g}$ & $36.40 \mathrm{~b}$ & Bad & Few & 6 & \\
\hline 5 & + & $175.17 \mathrm{~d}$ & $17.26 \mathrm{~d}$ & Moderate & Moderate & 16 & \\
\hline 6 & + & $164.52 \mathrm{e}$ & $17.01 \mathrm{~d}$ & Moderate & Moderate & 17 & \\
\hline 7 & + & $168.83 \mathrm{e}$ & $15.19 \mathrm{~d}$ & Moderate & Moderate & 11 & \\
\hline 8 & + & $176.02 d$ & $22.92 \mathrm{bc}$ & Excellent & Moderate & 16 & \\
\hline 9 & + & $165.77 \mathrm{e}$ & $16.49 \mathrm{c}$ & Moderate & Moderate & 12 & \\
\hline 10 & - & $129.78 \mathrm{~h}$ & $37.15 b$ & $\mathrm{Bad}$ & Few & 8 & \\
\hline 11 & - & $110.65 \mathrm{c}$ & $37.29 b$ & $\mathrm{Bad}$ & Few & 5 & \\
\hline 12 & + & $187.54 d$ & $14.45 \mathrm{e}$ & Bad & Few & 6 & \\
\hline 13 & + & $219.64 \mathrm{c}$ & $15.16 \mathrm{de}$ & Excellent & Moderate & 18 & \\
\hline 14 & - & $106.18 \mathrm{i}$ & $69.00 \mathrm{a}$ & Moderate & Moderate & 15 & \\
\hline 15 & + & $246.99 \mathrm{a}$ & $16.17 \mathrm{~d}$ & Excellent & Many & 26 & $\mathrm{R}$ \\
\hline 16 & + & $242.77 \mathrm{ab}$ & $16.80 \mathrm{~d}$ & Excellent & Many & 22 & \\
\hline 17 & - & $135.69 \mathrm{~g}$ & $30.81 \mathrm{bc}$ & $\mathrm{Bad}$ & Few & 10 & \\
\hline 18 & + & $226.43 \mathrm{~b}$ & $19.78 \mathrm{c}$ & Moderate & Moderate & 15 & \\
\hline 19 & - & $143.73 \mathrm{f}$ & $32.44 \mathrm{~b}$ & $\mathrm{Bad}$ & Moderate & 14 & \\
\hline 20 & + & $218.68 \mathrm{c}$ & $18.70 \mathrm{c}$ & Moderate & Moderate & 15 & \\
\hline 21 & + & $235.57 \mathrm{~b}$ & $18.00 \mathrm{~cd}$ & Excellent & Many & 18 & \\
\hline 22 & + & $226.94 b c$ & $17.99 \mathrm{~cd}$ & Excellent & Many & 23 & \\
\hline 23 & + & $235.93 b$ & $15.78 \mathrm{~cd}$ & Excellent & Many & 19 & \\
\hline 24 & - & $15.78 \mathrm{~cd}$ & $41.48 \mathrm{~b}$ & $\mathrm{Bad}$ & Few & 11 & \\
\hline 25 & + & $286.35 \mathrm{a}$ & $14.98 \mathrm{e}$ & Excellent & Many & 31 & $\mathrm{R}$ \\
\hline 26 & - & $179.96 \mathrm{~d}$ & $26.04 \mathrm{c}$ & $\mathrm{Bad}$ & Few & 13 & \\
\hline 27 & + & $248.87 \mathrm{a}$ & $12.38 \mathrm{e}$ & Excellent & Many & 27 & $\mathrm{R}$ \\
\hline 28 & + & $238.14 b$ & $14.45 \mathrm{~d}$ & Excellent & Many & 25 & \\
\hline 29 & + & $237.66 \mathrm{~b}$ & $10.60 \mathrm{f}$ & Excellent & Many & 26 & \\
\hline 30 & + & $265.11 \mathrm{a}$ & $8.77 \mathrm{~g}$ & Excellent & Many & 41 & $\mathrm{R}$ \\
\hline 31 & - & $150.00 \mathrm{f}$ & $49.69 a$ & $\mathrm{Bad}$ & Few & 18 & \\
\hline CK1 & - & $149.25 \mathrm{f}$ & $33.65 b$ & Bad & Few & 17 & \\
\hline CK2 & - & $157.19 \mathrm{f}$ & $30.14 b c$ & $\mathrm{Bad}$ & Few & 15 & \\
\hline CK3 & - & $183.44 d$ & $29.87 \mathrm{c}$ & $\mathrm{Bad}$ & Few & 15 & \\
\hline
\end{tabular}

*Duncan's new multiple range method was applied for significance test. a-i: indicate a 0.05 level of significance

temperature was particularly as high as $34^{\circ} \mathrm{C}$. Under this condition, the SOD activity reflected the heat capacity of the plant itself, and MDA concentration reflected the degree of heat damage. In table 1, high SOD activity but low MDA content were appeared in PCR-positive plants and the number of spike grain has a positive correlation with the SOD activity. It was illustrated that Taq DNA polymerase gene is beneficial to form the normal antioxidant enzyme, decrease the stress, enhance growth vigor, finally increase the kernel per spike.

\section{Discussion}

Currently, researches about maize heat tolerance were seldom carried out than drought or chill. Also, a complete system for identification of maize heat tolerance is lacked, especially reliable and effective criterion. The existing studies were ether only on seedling stage, or under artificial high temperature condition, which cannot be linked with flowering or seed setting (Hussain et al., 2006). The paper studied the experiment under the real field condition by postponing the sowing date and imposing high temperature during maize flowering period to trigger heat stress. The formation of plant resistance is often closely related to the activity of enhanced antioxidant enzyme system, in which SOD and MDA were usually taken as heat tolerance physiology index (Bowler, and Fluhr, 2000; Vranova et al., 2002). Also, growth vigor, pollen quantity and blade color were used as direct field index, while kernel number per spike was used as indirect parameter. Combined with positive PCR, above indexes can comprehensively screen transgenic heat tolerance lines. This system has a direct production application value.

Taq DNA polymerase shows the potential to maintain its activity at $94^{\circ} \mathrm{C}$, and the ability to catalyze DNA synthesis in a relatively wide temperature range. Thus, it forms a good heat-resistant gene resource in the field of plant genetic engineering. Now, a few heat-stable genes have been used in the development of expression vectors. For instance, heat shock protein gene, HSP (Dietrich et al., 1991), phytase gene, phyA (Li and Liu, 2004) and thermotolerance genes, TTOs (Ko et al., 2007). The expression vector with Taq DNA polymerase gene, developed in the present study, will certainly expand more avenues for heattolerant genetic transformation in plants. Particularly, in southern China, where asynchronous silking is associated 
with hot and humid weather conditions as well as abnormal temperature fluctuations during summer, nurturing new heat-tolerant species will have far-reaching significance and broad developmental prospects.

\section{Conclusion}

In this study, we developed heat-tolerant maize transgenic lines using Taq DNA polymerase gene, which will benefit to controlling crop loss due to heat stress and increase the economic value. SOD activity, MDA concentration, PCRpositive plants and growth vigor, as well as the number of spike grain, all should be used as heat tolerance index to form an ideal heat-tolerant screening system.

\section{Acknowledgments}

This work was supported in part by grants of "thermo tolerant maize line from transgenic sweet and glutinal maize, No. 2012B020301004", funded by Guangdong provincial department of science and technology, and "major project of new species cultivation through gene transformation, No. 2013ZX08003-001", funded by National Nature Science Foundation of China.

\section{Reference}

Andrade, T., E.V. Von Pinho, R.G. Von Pinho, G.E. Oliveira, V. Andrade and J.S. Fernandes, 2013. Physiological quality and gene expression related to heat-resistant proteins at different stages of development of maize seeds. Genet. Mol. Res., 12: 3630-3642

Bowler, C. and R. Fluhr, 2000. The role of calcium and activated oxygens as signals for controlling cross-tolerance, Trends Plant Sci., 5: 241246

Chen, Z., S. Wang, A. Wang and C.C. Wu, 2010. Genetic analysis of the tassel heat tolerance and the correlation with yield traits on maize. $J$. Maize Sci., 18: 7-12

Deeba, F., M.Z. Hyder, S.H. Shah and S.M. Naqvi, 2014. Multiplex PCR assay for identification of commonly used disarmed Agrobacterium tumefaciens strains. Springer Plus, 3: 358

Dietrich, P.S., R.A. Bouchard, E.S. Casey and R.M. Sinibaldi, 1991. Isolation and characterization of a small heat shock protein gene from maize. Plant Physiol., 96: 1268-1276

Di, H., Y. Zhou, G. Liang, P. Zhang, X. Lv, C. Lu and Z. Wang, 2012. Transformation of BcBCP1 gene into maize by three different pollen tube pathways. Crops, 2: 51-54

Eapen, S., 2011. Pollen grains as a target for introduction of foreign genes into plants: an assessment, Physiology and molecular biology of plants. Physiol. Mol. Biol. Plants, 17: 1-8

Frame, B., M. Main, R. Schick and K. Wang, 2011. Genetic transformation using maize immature zygotic embryos. Methods Mol. Biol., 710: $327-341$

Freiden, P.J., J.R. Gaut and L.M. Hendershot, 1992. Interconversion of three differentially modified and assembled forms of BiP. EMBO J., 11: 63-70

Hartl, F.U. and M. Hayer-Hartl, 2002. Molecular chaperones in the cytosol: from nascent chain to folded protein. Science, 295: 1852-1858
Hussain, T., I. Khan and M. Malik, 2006. Breeding potential for high temperature tolerance in maize (Zea mays L.). Pak. J. Bot., 38: 11851195

Jackson, M.A., D.J. Anderson and R.G. Birch, 2013. Comparison of Agrobacterium and particle bombardment using whole plasmid or minimal cassette for production of high-expressing, low-copy transgenic plants. Transgenic Res., 22: 143-151

Kaur, R. and V. Saxena, 2008. Association analysia of heat tolerant traits in spring maize (Zea mays L.). Crop Improvement, 32: 139-141

Ko, C.B., Y.M. Woo, D.J. Lee, M.C. Lee and C.S. Kim, 2007. Enhanced tolerance to heat stress in transgenic plants expressing the GASA4 gene. Plant Physiol. Biochem., 45: 722-728

$\mathrm{Li}$, J. and Z. Liu, 2004. Cloning of heat-stable phyA gene and construction of its new expression vector. J. Tongii Univ., 25: 41-44

Li, Z., J. Li and C. Du, 2002. Simultaneous measurement of five antioxidant enzyme activities using a single extraction systems. J. Yunnan Norm. Univ., 22: 45-48

Liang, X.L., J.Z. Du, Y.S. Hao, G.M. Cui, Y.X. Wang, X.Q. Wang, H.H. Zhang, D.Q. Sun and Y. Sun, 2016. Generation of Transgenic Maize by Two Germinating Seed Transformation Methods. Int. J. Agric. Biol., 18: 218-224

Miller, M., L. Tagliani, N. Wang, B. Berka, D. Bidney and Z.Y. Zhao, 2002. High efficiency transgene segregation in co-transformed maize plants using an Agrobacterium tumefaciens 2 T-DNA binary system. Transgenic Res., 11: 381-396

Mishra, R.C. and A. Grover, 2016. ClpB/Hsp100 proteins and heat stress tolerance in plants. Crit. Rev. Biotechnol., 36: 862-874

Morimoto, R.I., 1998. Regulation of the heat shock transcriptional response: cross talk between a family of heat shock factors, molecular chaperones, and negative regulators. Genes Dev, 12: 3788-3796

Omer, R.A., J.M. Matheka, A.M. Ali and J. Machuka, 2013. Transformation of tropical maize with the NPK1 gene for drought tolerance. Int. J. Genet. Eng., 3: 7-14

Schachman, H.K., J. Adler, C.M. Radding, I.R. Lehman and A. Kornberg, 1960. Enzymatic synthesis of deoxyribonucleic acid. VII. Synthesis of a polymer of deoxyadenylate and deoxythymidylate, J. Biol. Chem., 235: 3242-3249

Sheikholeslam, S.N. and D.P. Weeks, 1987. Acetosyringone promotes high efficiency transformation of Arabidopsis thaliana explants by Agrobacterium tumefaciens. Plant Mol. Biol., 8: 291-298

Stout, R.G. and T.S. Al-Niemi, 2002. Heat-tolerant flowering plants of active geothermal areas in Yellowstone National Park. Ann. Bot., 90: 259-267

Vega, J.M., W. Yu, A.R. Kennon, X. Chen and Z.J. Zhang, 2008. Improvement of Agrobacterium-mediated transformation in Hi-II maize (Zea mays) using standard binary vectors. Plant Cell Rep., 27: 297-305

Vranova, E., D. Inze and F. Van Breusegem, 2002. Signal transduction during oxidative stress. J. Exp. Bot., 53: 1227-1236

Wahid, A., S. Gelani, M. Ashraf and M.R. Foolad, 2007. Heat tolerance in plants: An overview. Environ. Exp. Bot., 61: 199-223

Wang, J., Y. Sun and Y. Li, 2007. Maize (Zea mays) genetic transformation by co-cultivating germinating seeds with Agrobacterium tumefaciens. Biotechnol. Appl. Biochem., 46: 51-55

Yang, S., R. Ohen, J. Zhao and Y. Mao, 1995. Spontaneous enzymatic synthesis of DNA catalyzed by thermostable DNA polymerase. $J$ Fudan Univ., 34: 391-397

Yang, S., W. Ni, C. Ge, J. Zhu, Z. Wang and S. Luo, 2007. Distribution of exogenous DNA in upland cotton by pollen tube pathway. J. Nucl. Agric. Sci., 21: 13-16

Zhou, G., 1983. Introduction of exogenous DNA into cotton embryos 1J2. Methods Enzymol., 101: 433-438

(Received 22 December 2016; Accepted 08 February 2017) 